\title{
Efficacy and safety of docetaxel for advanced non-small-cell lung cancer: a meta-analysis of Phase III randomized controlled trials
}

This article was published in the following Dove Press journal:

OncoTargets and Therapy

4 August 2015

Number of times this article has been viewed

Xuan $\mathrm{He}^{1}$

Ji Wang ${ }^{2}$

Yuanmin $\mathrm{Li}^{3}$

'State Key Laboratory of Biotherapy, ${ }^{2}$ Department of Evidence-Based Medicine and Clinical Epidemiology, ${ }^{3}$ Key Laboratory of Transplant Engineering and Immunology, Ministry of Health, West China Hospital, Sichuan University, Chengdu, Sichuan, People's Republic of China
Correspondence: Xuan He State Key Laboratory of Biotherapy, West China Hospital, Sichuan University, 17, the 3rd Section of South Renmin Road, Chengdu 6I004I, Sichuan, People's Republic of China

Tel +86I8683426699

Email hexuan9014@I63.com
Background: Several clinical trials have performed risk-benefit analyses comparing docetaxel and pemetrexed or docetaxel and vinca alkaloid, but the efficacy and safety remain uncertain. The aim was to conduct a meta-analysis to compare the efficacy and safety of docetaxel and pemetrexed or docetaxel and vinca alkaloid for non-small-cell lung cancer.

Methods: This meta-analysis of Phase III randomized controlled trials was performed after searching PubMed, Embase, the Cochrane Library, and the ISI Web of Knowledge for randomized controlled trials. Outcome analyses were overall survival, progression-free survival, and overall response rate with $95 \%$ confidence intervals and major grade $3 / 4$ toxicity.

Results: Seven eligible trials involving 2,080 patients were retrieved for analysis. Docetaxel enhanced progression-free survival and overall response rate compared with vinca alkaloid as first-line treatment $(P<0.05)$. However, there was no difference between docetaxel and pemetrexed as both first-line and second-line treatment $(P>0.05)$. With regard to the grade $3 / 4$ toxicity, compared with pemetrexed, docetaxel led to higher neutropenia and febrile neutropenia $(P<0.05)$, but there was no difference in non-hematological toxicity $(P>0.05)$. Docetaxel led to a lower rate of anemia as first-line treatment $(P<0.05)$. Moreover, docetaxel caused less grade 3/4 hematological and non-hematological toxicity compared with vinca alkaloid.

Conclusion: Docetaxel leads to a better result than vinca alkaloid in effectiveness and safety on patients with advanced non-small-cell lung cancer as first-line therapy. Docetaxel also causes lower toxicity as second-line therapy compared with vinca alkaloid. However, the differences in efficacy and safety between docetaxel and pemetrexed are not obvious. Further clinical study with more details, such as sex, age, histology, and so on, should be considered for illustrating the differences between these two drugs.

Keywords: docetaxel, NSCLC, risk-benefit analysis, systematic review

\section{Introduction}

Lung cancer, accounting for approximately $13 \%$ of total cancer diagnoses, remains one of the major causes of cancer-related death for humans worldwide with an estimated 1.8 million new lung cancer cases occurred in 2012. ${ }^{1}$ In People's Republic of China, it has been the leading diagnosed cancer and the cause of cancer-related death for many years, with a poor survival rate. ${ }^{2}$ It is reported that the annual new cases of lung cancer will rise to over one million by the year $2025 .{ }^{3}$ Non-small-cell lung cancer (NSCLC), with the most devastating and refractory features compared with other cancers, accounts for approximately $80 \%$ of lung cancers. Most patients with NSCLC present with advanced, inoperable disease (stage IIIB or IV). The median survival rarely exceeds 8 months, and less than $30 \%$ of patients can survive more than 1 year. Furthermore, approximately $60 \%$ of patients will require a second-line 
treatment, with a median time to progression of less than 3 months. ${ }^{4,5}$ Overall, NSCLC is a challenging human health problem.

Docetaxel is a semisynthetic taxoid derived from Taxus baccata. It is approved as first-line therapy in combination with cisplatin, as single-agent second-line therapy, or as single-agent maintenance therapy for patients with advanced NSCLC in numerous countries. ${ }^{6,7}$ Docetaxel combined with platinum-based agent (cisplatin or carboplatin) is generally considered the first-line treatment for patients with advanced NSCLC. ${ }^{8}$ Phase II trials of docetaxel and carboplatin combinations have resulted in median survival rates ranging between 8.4 and 13.9 months, indicating that such combinations are active as first-line therapies. ${ }^{9}$ Docetaxel not only benefits chemotherapy-naïve patients, but is also effective for those patients who have previously received platinum-based chemotherapy as the second-line treatment. A Phase II multicenter trial confirmed the antitumor activity and enhanced survival rate with docetaxel therapy in platinum-refractory NSCLC. The median survival time was 7 months, the 1-year survival rate was $25 \%$, and docetaxel was relatively well tolerated in this previously treated population. ${ }^{10}$

Apart from docetaxel, pemetrexed and vinca alkaloid are also representatives of NSCLC drugs and are widely used in current NSCLC treatment. Pemetrexed is a multitargeted inhibitor of the folate metabolic pathway, and its effectiveness in NSCLC compared with docetaxel has been demonstrated in several clinical trials. ${ }^{11,12}$ Vindesine, an analog of vinca alkaloid, and its analogs, are classical drugs for NSCLC treatment. ${ }^{13}$ Pemetrexed and vinca alkaloid are both applied as first- and second-line treatment in NSCLC. ${ }^{3,14}$ Furthermore, docetaxel, pemetrexed, and vinca alkaloid are commonly applied drugs for NSCLC treatment in People's Republic of China. ${ }^{15,16}$ In order to obtain a more detailed risk-benefit analysis of docetaxel, several clinical trials have investigated the effectiveness and safety between docetaxel and pemetrexed or docetaxel and vinca alkaloid. However, most of these trials have small samples, which supply limited data to evaluate the effectiveness and safety of these drugs. Furthermore, some studies even produced contrary results, especially in terms of the toxicities. In addition, there is no systematic review or meta-analysis comparing docetaxel with pemetrexed or vinca alkaloid considering the treatment in different lines. Therefore, we intended to conduct a systematic review and meta-analysis for all the eligible Phase III randomized controlled trials and to compare the risk-benefit information between docetaxel and other representative NSCLC drugs such as pemetrexed or vinca alkaloid in order to get a more credible result and evaluate the benefit of docetaxel for NSCLC treatment.

\section{Materials and methods Search strategy}

Comprehensive searches for eligible trials were performed by an electronic search of the Cochrane Library, PubMed, Embase, and the ISI Web of Knowledge using the following terms: (docetaxel OR taxotere) AND (lung cancer OR lung tumor OR lung neoplasm). The time searched was from the establishment time of each database to January 24, 2015.

\section{Eligibility criteria}

Eligible studies had to meet the following four criteria: 1) clinical Phase III randomized controlled trials with a parallel design comparing docetaxel and pemetrexed or docetaxel and vinca alkaloid in advanced NSCLC patients; 2) they had to be randomized controlled trials, and the blinded and unblinded ones were all eligible; 3) studies had full text articles available; and 4) studies included three or more sufficient data such as overall response rate (ORR), median survival time, progression-free survival (PFS), disease control rate, and toxicities reflecting the two different treatments.

\section{Data collection}

Two investigators (Xuan He and Yuanmin Li) independently scanned titles or abstracts to exclude studies which failed to meet the mentioned criteria and then obtained, reviewed, and extracted the full text reports for further assessment. Disagreements were resolved by consensus. Detailed data of eligible trials such as study design, participants' information, methodological evaluation, intervention outcomes, and adverse event reports were extracted.

\section{Quality assessment}

Evaluation of the methodological quality of the included studies was performed by two investigators (Xuan He and Ji Wang) independently. The Jadad scoring system was used as follows: a quality review of each randomized controlled trial was performed by examining details of randomization, generation of random numbers, details of the double-blinding procedure, information on withdrawals, and concealment of allocation. ${ }^{17}$ One point was awarded for the specification of each of the above criteria; the maximum score for a study was 5. A high-quality randomized controlled trial score was not less than 3 points, while a low-quality randomized controlled trial score was 2 or lower points, according to the reported methodology. ${ }^{18}$ 


\section{Statistical analysis}

Time-to-event outcomes were compared using a hazard ratio (HR). Dichotomous data were compared using an odds ratio (OR). Statistical heterogeneity in the results of the trials was assessed by the chi-square test and expressed by the $I^{2}$ index. ${ }^{19}$ A pooled effect was calculated with a fixed-effects model, if there was no statistically significant heterogeneity, whereas if considerable heterogeneity was found $(P<0.1$ or $I^{2}>50 \%$ ), a random-effects model was employed. All $P$-values were two-sided and confidence intervals (CIs) had two-sided probability coverage of $95 \%$. The meta-analysis was performed using Review Manager 5.3.

\section{Results}

\section{Search results and characteristics of included trials}

A total of 2,514 potential relevant articles were identified for initial screening. After exclusion of duplicate and irrelevant studies, our search yielded seven eligible trials, which involved 2,080 patients, that were retrieved for analysis. There were 1,048 and 1,032 patients randomized to docetaxel and to other anti-NSCLC drug arms, respectively. Of the included studies, three studies compared docetaxel and pemetrexed, ${ }^{20-22}$ two studies compared docetaxel and vinorelbine, ${ }^{23,24}$ and two studies compared docetaxel and vinorelbine analogs (vinflunine or vindesine) ${ }^{25,26}$ The process of study selection is shown in a flowchart (Figure 1). Characteristics of the included trials are provided in Table 1 . The Jadad score was used to assess the quality of the included trials. Overall, two trials scored 4, while the others scored 3.

\section{Overall survival}

We performed subgroup analysis in first-line and secondline, respectively, in order to distinguish the efficacy of the different lines of treatment. Five trials provided HR results of overall survival (OS) ${ }^{20-22,24,25}$ No significant difference was found in the pooled HR for OS between docetaxel and pemetrexed as both first-line and second-line treatment (HR 1.10, 95\% CI: 0.76-1.59, $P=0.62$; HR 1.05, 95\% CI: $0.88-1.24, P=0.60$, respectively). Results were similar in the comparison of docetaxel with vinca alkaloid. OS for docetaxel versus vinca alkaloid as first-line treatment was not statistically different (HR $0.78,95 \%$ CI: $0.56-1.08$, $P=0.14)$. In addition, there was also no difference in OS between docetaxel and vinca alkaloid as second-line treatment (HR 0.97, 95\% CI: 0.80-1.18, $P=0.78$ ) (Figure 2).

\section{PFS}

HR results of PFS were offered by four clinical trials..$^{20,22,24,25}$ Similar to the result of OS, there was no significant difference in PFS between docetaxel and pemetrexed as both first-line and second-line treatment (HR 1.10, 95\% CI: 0.81-1.49, $P=0.54$; HR $1.03,95 \%$ CI: $0.86-1.23, P=0.74$, respectively). In terms of docetaxel with vinca alkaloid as first-line treatment, there was a significant statistical difference in PFS (HR $0.63,95 \%$ CI: $0.45-0.82, P=0.001)$. However, docetaxel was associated with no significant improvement in PFS compared

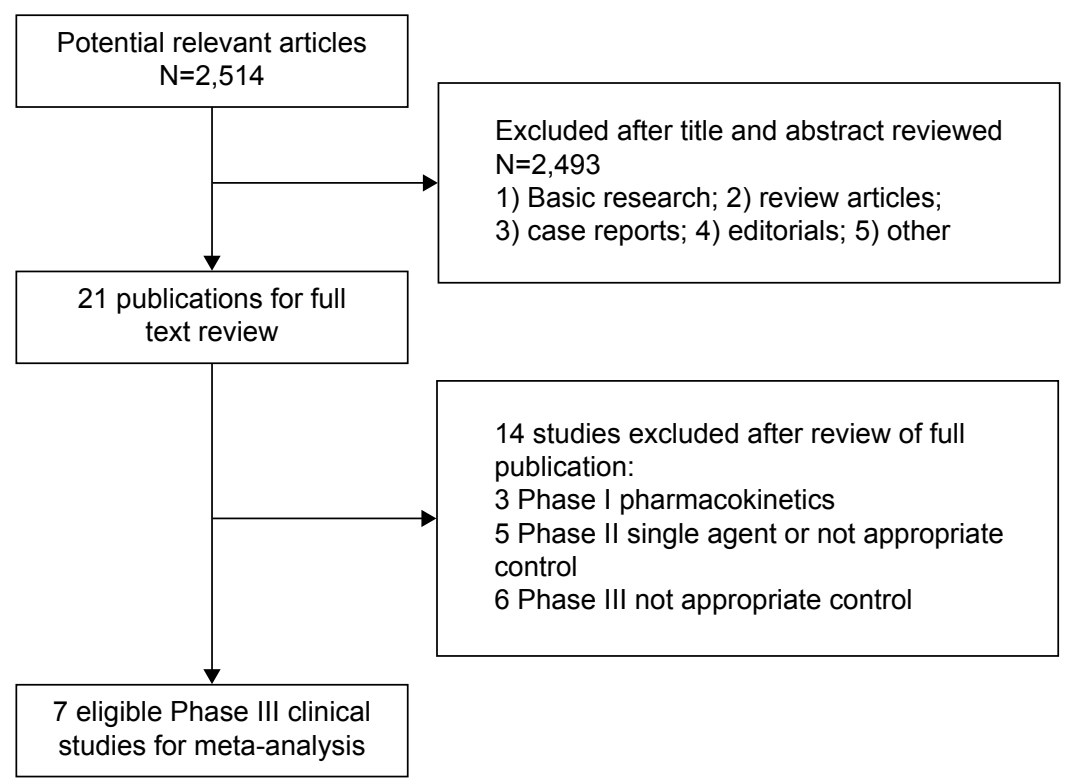

Figure I Flow diagram showing the trial selection process for the meta-analysis. 
Table I Characteristics of the seven eligible Phase III randomized trials in this meta-analysis

\begin{tabular}{|c|c|c|c|c|c|c|c|c|}
\hline Study & $\begin{array}{l}\text { Study } \\
\text { region }\end{array}$ & Intervention & Number & $\begin{array}{l}\text { Median age } \\
\text { (years) }\end{array}$ & Male (\%) & Stage & Outcome & $\begin{array}{l}\text { Jadad } \\
\text { score }\end{array}$ \\
\hline \multirow[t]{2}{*}{ Rodrigues-Pereira et a ${ }^{20}$} & Argentina & Doc $\left(75 \mathrm{mg} / \mathrm{m}^{2}\right)+$ Carb & 105 & 58.9 & 47.6 & Stage IIIB/IV & SWT, OS, & 3 \\
\hline & & Pem $\left(500 \mathrm{mg} / \mathrm{m}^{2}\right)+$ Carb & 106 & 60.1 & 60.4 & & PFS & \\
\hline \multirow[t]{2}{*}{ Karampeazis et al ${ }^{23}$} & Greece & $\operatorname{Doc}\left(38 \mathrm{mg} / \mathrm{m}^{2}\right)$ & 66 & 75.5 & 92.4 & Stage IIIB/IV & OS, ORR, & 4 \\
\hline & & $\operatorname{Vin}\left(25 \mathrm{mg} / \mathrm{m}^{2}\right)$ & 64 & 77 & 93.8 & & TTP, Toxl & \\
\hline \multirow[t]{2}{*}{ Vergnenegre et $\mathrm{a}^{21}$} & France & $\operatorname{Doc}\left(75 \mathrm{mg} / \mathrm{m}^{2}\right)$ & 75 & 64 & 85.3 & Stage IIIB/IV & OS, PFS, & 3 \\
\hline & & Pem $\left(500 \mathrm{mg} / \mathrm{m}^{2}\right)$ & 75 & 62 & 82.7 & & ORR, Toxl & \\
\hline \multirow[t]{2}{*}{ Krzakowski et a ${ }^{25}$} & France & $\operatorname{Doc}\left(75 \mathrm{mg} / \mathrm{m}^{2}\right)$ & 275 & 60 & 75.3 & Stage III/IV & PFS, ORR, & 4 \\
\hline & & $\mathrm{Vfl}\left(320 \mathrm{mg} / \mathrm{m}^{2}\right)$ & 262 & 61.9 & 75 & & OS & \\
\hline \multirow[t]{2}{*}{ Kudoh et $\mathrm{al}^{24}$} & Japan & $\operatorname{Doc}\left(60 \mathrm{mg} / \mathrm{m}^{2}\right)$ & 88 & 76 & 77.5 & Stage IIIB/IV & OS, PFS, & 3 \\
\hline & & $\operatorname{Vin}\left(25 \mathrm{mg} / \mathrm{m}^{2}\right)$ & 91 & 76 & 74.7 & & ORR, Toxl & \\
\hline \multirow[t]{2}{*}{ Hanna et $\mathrm{a}^{22}$} & United & $\operatorname{Doc}\left(75 \mathrm{mg} / \mathrm{m}^{2}\right)$ & 288 & 57 & 75.3 & Stage III/IV & OS, PFS, & 3 \\
\hline & States & Pem $\left(500 \mathrm{mg} / \mathrm{m}^{2}\right)$ & 283 & 59 & 68.6 & & ORR, Toxl & \\
\hline \multirow[t]{2}{*}{ Kubota et al ${ }^{26}$} & Japan & $\operatorname{Doc}\left(60 \mathrm{mg} / \mathrm{m}^{2}\right)+$ Cis & $15 \mid$ & 63 & 64.2 & Stage IV & OS, ORR, & 3 \\
\hline & & $\operatorname{Vds}\left(3 \mathrm{mg} / \mathrm{m}^{2}\right)+\mathrm{Cis}$ & $|5|$ & 64 & 68.2 & & Toxl & \\
\hline
\end{tabular}

Abbreviations: Doc, docetaxel; Carb, carboplatin; Pem, pemetrexed; Vin, vinorelbine; Vfl, vinflunine; Vds, vindesine; Cis, cisplatin; SWT, survival without grade 3 or 4 toxicity; OS, overall survival; PFS, progression-free survival; ORR, overall response rate; TTP, time to tumor progression; Toxl, toxicity indexes.

with vinca alkaloid as second-line treatment (HR 1.00, 95\% CI: 0.83-1.19, $P=0.96$ ) (Figure 3).

\section{ORR}

Six trials reported the outcome of ORR in NSCLC therapy. Result of the $I^{2}$ was below $50 \%$ and the fixed-effects model was applied. ${ }^{21-26}$ There were no ORR data available for the comparison between docetaxel and pemetrexed as first-line treatment. No significant statistical difference in ORR was detected in docetaxel versus pemetrexed as second-line treatment (OR 0.92, 95\% CI: $0.56-1.52, P=0.76$ ). In terms of first-line treatment, compared with vinca alkaloid, docetaxel was associated with significant improvement of ORR (OR $1.98,95 \%$ CI: $1.33-2.95, P=0.0008)$. In addition, there was a similar result for ORR between docetaxel and vinca alkaloid as second-line treatment (OR 1.20, 95\% CI: 0.55-2.62, $P=0.64$ ) (Figure 4).

\section{Grade 3/4 hematological and non- hematological toxicity}

Tables 2-5 are the summaries of forest plots for grade 3/4 hematological and non-hematological toxicity. All seven

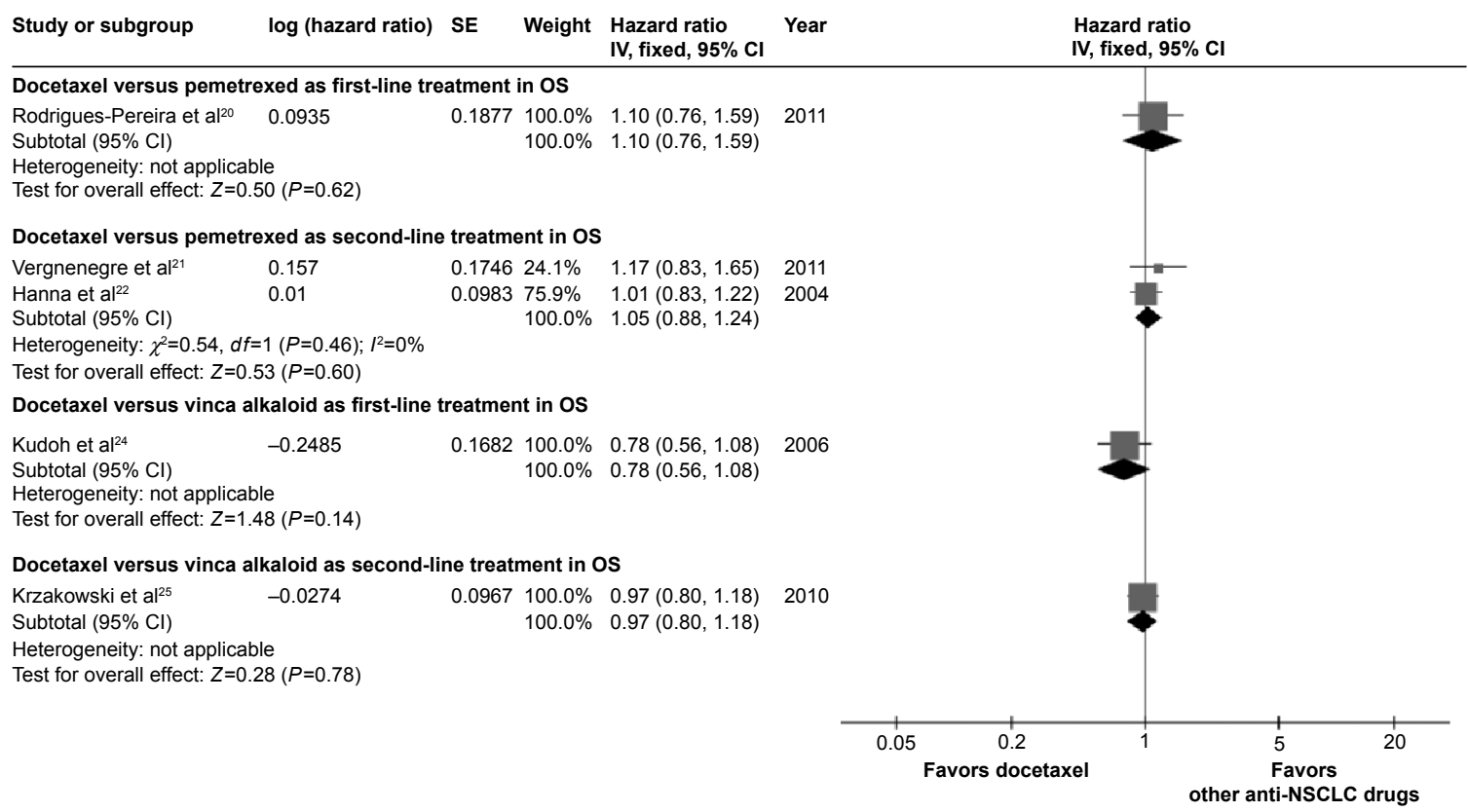

Figure 2 Comparison of OS between docetaxel and other anti-NSCLC drug interventions.

Abbreviations: $\mathrm{Cl}$, confidence interval; IV, inverse variance; NSCLC, non-small-cell lung cancer; OS, overall survival; SE, standard error. 


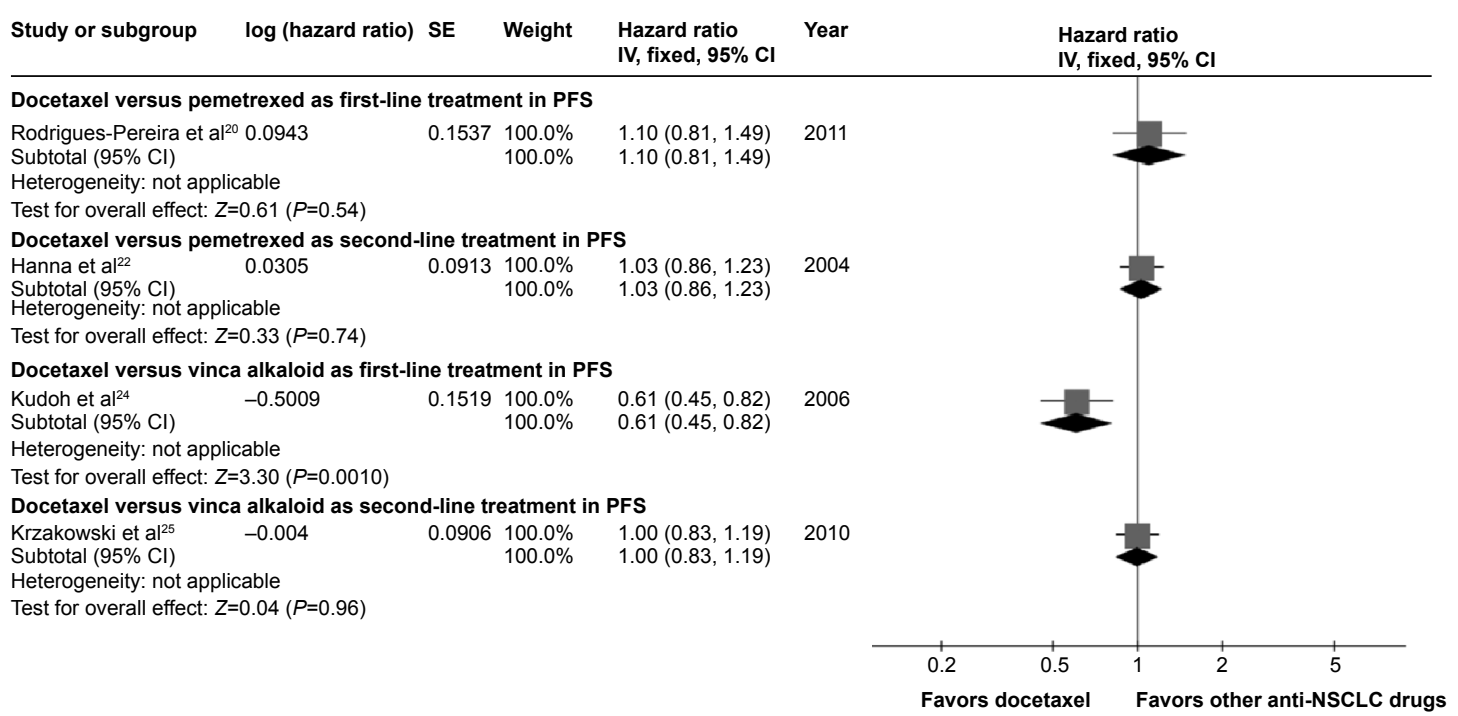

Figure 3 Comparison of PFS between docetaxel and other anti-NSCLC drug interventions.

Abbreviations: $\mathrm{Cl}$, confidence interval; IV, inverse variance; NSCLC, non-small-cell lung cancer; OS, overall survival; PFS, progression-free survival; SE, standard error.

trials reported hematological toxicity, including neutropenia, anemia, and thrombocytopenia, as well as non-hematological toxicity including diarrhea, nausea, and vomiting. ${ }^{20-26} \mathrm{Com}-$ pared with pemetrexed, docetaxel led to a higher rate of grade 3/4 toxicity as first-line treatment in neutropenia, leukopenia, and febrile neutropenia. On the contrary, it caused fewer instances of anemia. There were no statistically significant differences in thrombocytopenia and non-hematological toxicity (Table 2). Moreover, docetaxel caused a higher rate of grade $3 / 4$ toxicity as second-line treatment in neutropenia and febrile neutropenia compared with pemetrexed, whereas a lower rate of thrombocytopenia and no difference in anemia and non-hematological toxicity were observed (Table 3 ). Compared with vinca alkaloid, there was a lower rate of toxicity with docetaxel treatment. The grade $3 / 4$ toxicity symptom anemia occurred less frequently with docetaxel compared with vinca alkaloid as first-line treatment. However, diarrhea was more common with docetaxel compared with vinca alkaloid (Table 4). In addition, docetaxel led to a decreased rate of the grade $3 / 4$ toxicity symptoms anemia

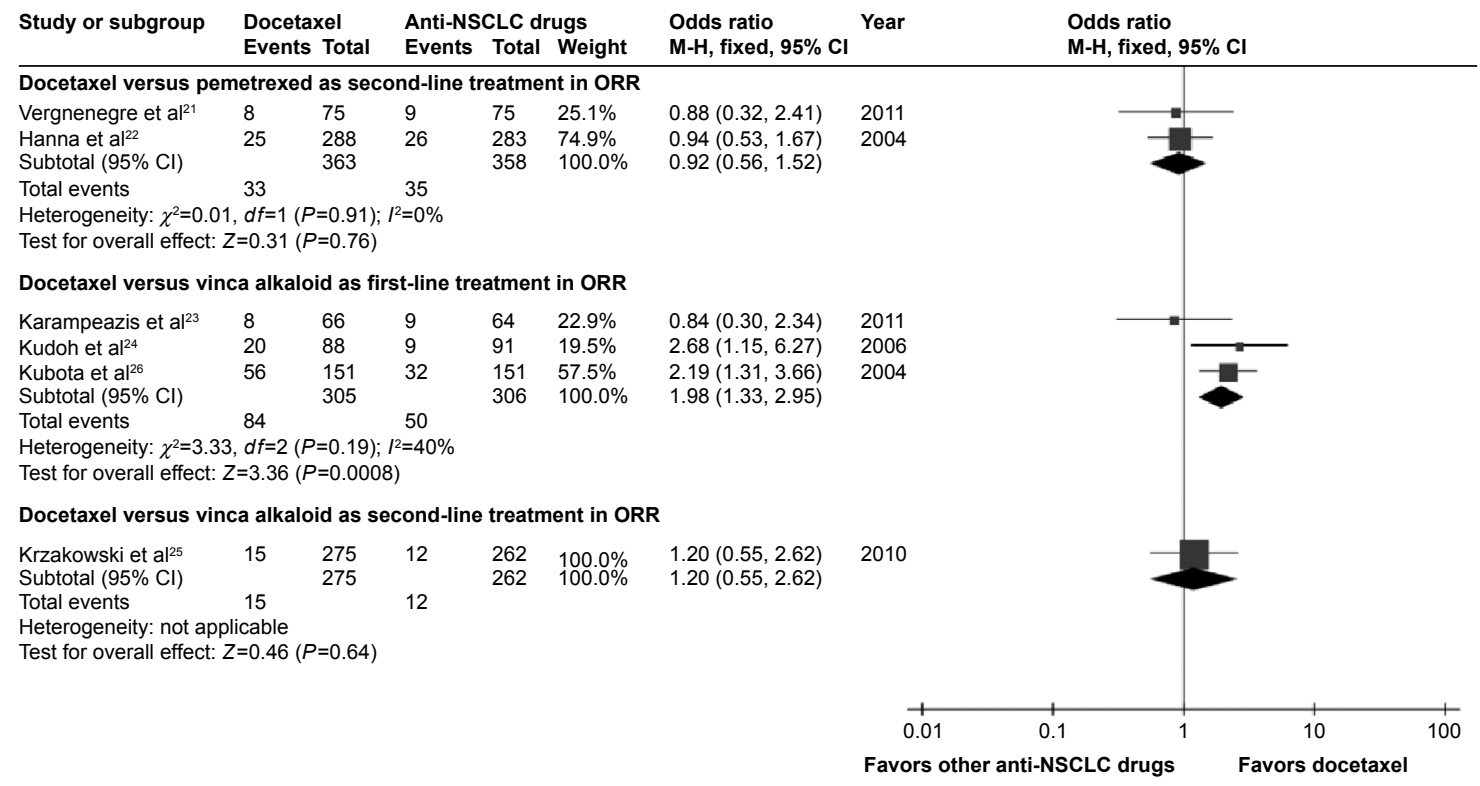

Figure 4 Comparison of ORR between docetaxel and other anti-NSCLC drug interventions.

Abbreviations: $\mathrm{Cl}$, confidence interval; $\mathrm{M}-\mathrm{H}$, Mantel-Haenszel test; NSCLC, non-small-cell lung cancer; ORR, overall response rate. 
Table 2 Comparison of grade 3/4 toxicity between docetaxel and pemetrexed as first-line treatment

\begin{tabular}{lllll}
\hline Grade 3/4 toxicity symptom & Docetaxel & Pemetrexed & OR (95\% Cl) & P-value \\
\hline Hematologic events & & & & \\
$\quad$ Neutropenia & $68 / 105$ & $35 / 106$ & $3.73(2.11,6.59)$ & 0.00001 \\
Anemia & $2 / 105$ & $13 / 106$ & $0.14(0.03,0.63)$ & 0.01 \\
$\quad$ Thrombocytopenia & $3 / 105$ & $10 / 106$ & $0.28(0.08,1.06)$ & 0.06 \\
Leukopenia & $42 / 105$ & $17 / 106$ & $3.49(1.82,6.68)$ & 0.0002 \\
$\quad$ Febrile neutropenia & $9 / 105$ & $0 / 106$ & $20.97(1.20,365.10)$ & 0.04 \\
Non-hematologic events & & & & 0.21 \\
$\quad$ Diarrhea & $4 / 105$ & $1 / 106$ & $4.16(0.46,37.84)$ & 0.99 \\
Nausea & $1 / 105$ & $1 / 106$ & $1.01(0.06,16.36)$ & 0.50 \\
$\quad$ Vomiting & $0 / 105$ & $1 / 106$ & $0.33(0.01,8.28)$ &
\end{tabular}

Abbreviations: $\mathrm{Cl}$, confidence interval; OR, odds ratio.

and thrombocytopenia compared with vinca alkaloid as second-line treatment (Table 5).

\section{Publication bias}

A comprehensive design was used in our study to minimize the publication bias. First, an intact search strategy was performed. Second, the inclusion criteria were strictly limited to selected eligible papers. Asymmetric tests were not carried out due to the limited number of studies in this research.

\section{Discussion}

Docetaxel is a semisynthetic taxoid analog that provides benefit in the treatment of many cancers, such as breast cancer, ovarian cancer, NSCLC, and prostate cancer, without severe adverse reaction occurring in paclitaxel. ${ }^{27}$ It is a potent inhibitor of mitosis through strengthening aggregation of tubulin and inhibiting depolymerization of microtubules. ${ }^{28,29}$ Docetaxel plays an important role, and has been proved to be the main therapy for advanced NSCLC. ${ }^{30}$ There are also novel or classical drugs for advanced NSCLC treatment, such as vinca alkaloid and pemetrexed. Vinca alkaloid is a commonly used anticancer drug for NSCLC treatment that is similar to docetaxel in terms of the mechanism of its interactions with tubulin and disruption of microtubule function, particularly when microtubules comprise the mitotic spindle apparatus, directly causing metaphase arrest. ${ }^{31}$ A Phase II trial of vinflunine, one kind of vinca alkaloid, in patients with NSCLC previously treated with a platinum-containing regimen yielded a response rate of $7.9 \%$ in the intent-to-treat analysis, suggesting a stable and promising chemotherapy. ${ }^{32}$ Pemetrexed is another new-generation antifolate for the treatment of mesothelioma and NSCLC due to its high affinity for three folate transporters. ${ }^{33}$ Study of pemetrexed in patients with advanced NSCLC, who had progressed during or within 3 months of completing first-line chemotherapy, demonstrated a response rate of $8.9 \%$ and median survival time of 5.7 months. ${ }^{34}$ The mechanism of docetaxel is similar to vinca alkaloid but different from pemetrexed, indicating a possible difference in efficacy and safety among these drugs in clinical application. Since docetaxel had not previously been comprehensively compared with these drugs, we conducted the systematic review and meta-analysis for all the eligible high-quality Phase III randomized controlled trials to compare the effectiveness and safety between docetaxel and pemetrexed or docetaxel and vinca alkaloid.

Table 3 Comparison of grade 3/4 toxicity between docetaxel and pemetrexed as second-line treatment

\begin{tabular}{|c|c|c|c|c|c|c|}
\hline \multirow[t]{2}{*}{ Grade 3/4 toxicity symptom } & \multirow[t]{2}{*}{ Docetaxel } & \multirow[t]{2}{*}{ Pemetrexed } & \multicolumn{2}{|c|}{ Heterogeneity } & \multirow[t]{2}{*}{ OR $(95 \% \mathrm{CI})$} & \multirow[t]{2}{*}{$P$-value } \\
\hline & & & $P$-value & $I^{2}$ & & \\
\hline \multicolumn{7}{|l|}{ Hematologic events } \\
\hline Neutropenia & $|37 / 35|$ & $20 / 340$ & 0.24 & $29 \%$ & $9.57(5.08,18.03)$ & $<0.0000$ I \\
\hline Anemia & $|3 / 35|$ & $16 / 340$ & 0.15 & $53 \%$ & $0.60(0.12,2.94)$ & 0.53 \\
\hline Thrombocytopenia & $2 / 351$ & $10 / 340$ & 1.00 & $0 \%$ & $0.19(0.04,0.87)$ & 0.03 \\
\hline Febrile neutropenia & $35 / 276$ & $5 / 265$ & - & - & 7.55 (2.91, 19.59) & $<0.0001$ \\
\hline \multicolumn{7}{|l|}{ Non-hematologic events } \\
\hline Diarrhea & $7 / 276$ & $1 / 265$ & - & - & $6.87(0.84,56.22)$ & 0.07 \\
\hline Nausea & $7 / 351$ & $9 / 340$ & 0.74 & $0 \%$ & $0.75(0.28,2.04)$ & 0.57 \\
\hline Vomiting & $5 / 351$ & $6 / 340$ & 0.79 & $0 \%$ & $0.8 \mathrm{I}(0.24,2.68)$ & 0.73 \\
\hline
\end{tabular}

Abbreviations: $\mathrm{Cl}$, confidence interval; OR, odds ratio. 
Table 4 Comparison of grade 3/4 toxicity between docetaxel and vinca alkaloid as first-line treatment

\begin{tabular}{|c|c|c|c|c|c|c|}
\hline \multirow{2}{*}{$\begin{array}{l}\text { Grade } 3 / 4 \text { toxicity } \\
\text { symptom }\end{array}$} & \multirow[t]{2}{*}{ Docetaxel } & \multirow{2}{*}{$\begin{array}{l}\text { Vinca } \\
\text { alkaloid }\end{array}$} & \multicolumn{2}{|c|}{ Heterogeneity } & \multirow[t]{2}{*}{ OR $(95 \% \mathrm{Cl})$} & \multirow[t]{2}{*}{$P$-value } \\
\hline & & & $P$-value & $P^{2}$ & & \\
\hline \multicolumn{7}{|l|}{ Hematologic events } \\
\hline Neutropenia & $165 / 305$ & $17 \mid / 306$ & 0.0001 & $89 \%$ & $0.67(0.19,2.32)$ & 0.53 \\
\hline Anemia & $18 / 305$ & $44 / 306$ & 0.97 & $0 \%$ & $0.37(0.20,0.65)$ & 0.0007 \\
\hline Thrombocytopenia & $1 / 305$ & $0 / 306$ & - & - & $3.02(0.12,74.72)$ & 0.50 \\
\hline Leukopenia & $120 / 239$ & $149 / 242$ & 0.003 & $89 \%$ & $0.7 \mathrm{I}(0.23,2.22)$ & 0.56 \\
\hline Febrile neutropenia & $12 / 154$ & $11 / 155$ & 0.91 & $0 \%$ & I.I $4(0.48,2.7 \mathrm{I})$ & 0.77 \\
\hline \multicolumn{7}{|l|}{ Non-hematologic events } \\
\hline Diarrhea & $19 / 305$ & $3 / 306$ & 0.83 & $0 \%$ & $5.94(1.88,18.73)$ & 0.002 \\
\hline Nausea & $23 / 305$ & $15 / 306$ & 0.72 & $0 \%$ & $1.59(0.82,3.10)$ & 0.17 \\
\hline Vomiting & $13 / 305$ & $8 / 306$ & 0.31 & $4 \%$ & $\mathrm{I} .64(0.68,3.97)$ & 0.27 \\
\hline
\end{tabular}

Abbreviations: $\mathrm{Cl}$, confidence interval; OR, odds ratio.

All the studies included in our meta-analysis were clinical Phase III trials, and all had a Jadad score of three or above and were defined as high quality. The results of the present meta-analysis reveal that there was an equivalent outcome in OS and PFS between docetaxel and pemetrexed as first-line treatment. There was also similar efficacy in terms of OS, PFS, and ORR on NSCLC as second application. The result is similar to several clinical trials. ${ }^{35,36}$ However, there was a confusing result for efficacy when comparing docetaxel with pemetrexed. ${ }^{37} \mathrm{~A}$ former randomized controlled trial pointed out that histology subgroup is the important factor affecting pemetrexed application. A more detailed subgroup analysis might be carried out in the future to obtain a deeper insight with further validation. In terms of subgroup analysis with vinca alkaloid, docetaxel enhanced PFS and ORR significantly and increased OS to some extent as first-line treatment. However, there was no difference between docetaxel and vinca alkaloid in second line. The result indicates that docetaxel in first-line treatment but not in second line has a better effect than vinca alkaloid.

Toxicity, associated with quality of life, is one of the most crucial indexes in anticancer drugs. Most clinical studies have been based on small samples, which are unable to offer adequate statistical results for evaluating the actual safety of these drugs. Several studies even produced conflicting results, especially in aspects of their toxicities. For instance, Klionsky et al reported that there was no significant difference in terms of thrombocytopenia between docetaxel and pemetrexed; however, Sun et al reported docetaxel caused a higher rate of thrombocytopenia. ${ }^{38,39}$ In order to obtain a precise result, we only included large-sample Phase III trials for toxicity assessment. It also led to anemia compared with pemetrexed as the first-line treatment. However, there was no difference between docetaxel and pemetrexed as the second-line treatment. Therefore, there was no significant difference in occurrence of neutropenia, thrombocytopenia, leukopenia, and febrile neutropenia between docetaxel and vinca alkaloid. Pemetrexed led to fewer occurrences of neutropenia and febrile neutropenia than docetaxel. Also, thrombocytopenia occurred less with docetaxel compared with pemetrexed. Docetaxel led to no difference compared with pemetrexed/vinca alkaloid in non-hematologic events. However, docetaxel caused less diarrhea compared with vinca alkaloid as first-line treatment.

According to the results of our study, docetaxel is a more effective and safer agent as first-line therapy in NSCLC

Table 5 Comparison of grade 3/4 toxicity between docetaxel and vinca alkaloid as second-line treatment

\begin{tabular}{|c|c|c|c|c|}
\hline Grade 3/4 toxicity symptom & Docetaxel & Vinca alkaloid & OR $(95 \% \mathrm{Cl})$ & $P$-value \\
\hline \multicolumn{5}{|l|}{ Hematologic events } \\
\hline Neutropenia & $82 / 277$ & $90 / 274$ & $0.86(0.60,1.23)$ & 0.41 \\
\hline Anemia & $8 / 277$ & $20 / 274$ & $0.38(0.16,0.87)$ & 0.02 \\
\hline Thrombocytopenia & $\mathrm{I} / 277$ & $6 / 274$ & $0.16(0.02,1.35)$ & 0.09 \\
\hline Leukopenia & $59 / 277$ & $64 / 274$ & $0.89(0.59,1.33)$ & 0.56 \\
\hline Febrile neutropenia & 13/277 & $9 / 274$ & $\mathrm{I} .45(0.6 \mathrm{I}, 3.45)$ & 0.40 \\
\hline \multicolumn{5}{|l|}{ Non-hematologic events } \\
\hline Diarrhea & $5 / 277$ & $2 / 274$ & $2.50(0.48,13.00)$ & 0.28 \\
\hline Nausea & $3 / 277$ & $4 / 274$ & $0.74(0.16,3.33)$ & 0.69 \\
\hline Vomiting & $3 / 277$ & $5 / 274$ & $0.59(0.14,2.49)$ & 0.47 \\
\hline
\end{tabular}

Abbreviations: $\mathrm{Cl}$, confidence interval; OR, odds ratio. 
compared with vinca alkaloid. As for second-line treatment, docetaxel causes no effective difference except for lower toxicity occurrence when compared with vinca alkaloid. There was no difference in efficacy between docetaxel and pemetrexed. However, docetaxel leads to a higher rate of neutropenia and lower rate of anemia symptom compared with pemetrexed in clinical application.

Certainly, there are several limitations in our study. First of all, due to limited or missing data about subsets in current trials, details such as nationality, sex, age, histology, and cancer stage were unable to be analyzed. Secondly, although docetaxel and other anti-NSCLC drugs have already been widely used as chemotherapy for advanced NSCLC, related randomized clinical trials seem to be limited. Finally, the quality of included trials (five trials scored 3, two trials scored 4) still needs further improvement.

Considering the limitations above, it is not easy to control many inherent factors associated with the studies of interventions relating to docetaxel and other anti-NSCLC drugs, hence the results of our review must be interpreted with caution.

\section{Conclusion}

In terms of the effectiveness and safety on patients with advanced NSCLC in first-line therapy, docetaxel leads to a better result than vinca alkaloid. Docetaxel also causes lower toxicity in second-line therapy compared with vinca alkaloid. However, the differences in efficacy and safety between docetaxel and pemetrexed are not obvious. Therefore, further clinical study with more details, such as sex, age, histology, and so on, should be considered for illustrating the differences between these two drugs.

\section{Disclosure}

The authors report no conflicts of interest in this work.

\section{References}

1. Torre LA, Bray F, Siegel RL, Ferlay J, Lortet-Tieulent J, Jemal A. Global cancer statistics, 2012. CA Cancer J Clin. 2015;65:87-108.

2. Zheng RS, Zeng HM, Zhang SW, et al. Lung cancer incidence and mortality in China, 2010. Thorac Cancer. 2014;5:330-336.

3. Sun Y, Wu YL, Zhou CC, et al. Second-line pemetrexed versus docetaxel in Chinese patients with locally advanced or metastatic nonsmall cell lung cancer: a randomized, open-label study. Lung Cancer. 2013;79:143-150.

4. Govindan R, Page N, Morgensztern D, et al. Changing epidemiology of small-cell lung cancer in the United States over the last 30 years: analysis of the surveillance, epidemiologic, and end results database. J Clin Oncol. 2006;24:4539-4544.

5. Di BS, Wei KP, Tian JH, et al. Effectiveness and safety of pemetrexed versus docetaxel as a treatment for advanced non-small cell lung cancer: a systematic review and meta-analysis. Asian Pac J Cancer Prev. 2014; 15:3419-3424.
6. Molina JR, Yang P, Cassivi SD, Schild SE, Adjei AA. Non-small cell lung cancer: epidemiology, risk factors, treatment, and survivorship. Mayo Clin Proc. 2008;83:584-594.

7. Peters S, Adjei AA, Gridelli C, Reck M, Kerr K, Felip E; ESMO Guidelines Working Group. Metastatic non-small-cell lung cancer (NSCLC): ESMO Clinical Practice Guidelines for diagnosis, treatment and follow-up. Ann Oncol. 2012;23 Suppl 7:vii56-vii64.

8. Schiller JH, Harrington D, Belani CP, et al; Eastern Cooperative Oncology Group. Comparison of four chemotherapy regimens for advanced nonsmall-cell lung cancer. $N$ Engl J Med. 2002;346:92-98.

9. Kim HJ, Kim TG, Lee HJ, et al. A phase II study of combination chemotherapy with docetaxel and carboplatin for elderly patients with advanced non-small cell lung cancer. Lung Cancer. 2010;68: 248-252.

10. Gandara DR, Vokes E, Green M, et al. Activity of docetaxel in platinumtreated non-small-cell lung cancer: results of a phase II multicenter trial. J Clin Oncol. 2000;18:131-135.

11. Adjei AA. Pharmacology and mechanism of action of pemetrexed. Clinical Lung Cancer. 2004;5:51-55.

12. Pujol JL, Paul S, Chouaki N, et al. Survival without common toxicity criteria grade $3 / 4$ toxicity for pemetrexed compared with docetaxel in previously treated patients with advanced non-small cell lung cancer (NSCLC): a risk-benefit analysis. J Thorac Oncol. 2007;2:397-401.

13. Barletta G, Genova C, Rijavec E, et al. Oral vinorelbine in the treatment of non-small-cell lung cancer. Expert Opin Pharmacother. 2014;15: $1585-1599$.

14. Chang A. Chemotherapy, chemoresistance and the changing treatment landscape for NSCLC. Lung Cancer. 2011;71:3-10.

15. Cui DH. Penetrated and docetaxel respectively combined with cisplatin in the treatment of non-small cell lung cancer. Chinese Journal of Clinical Oncology and Rehabilitation. 2014;21:820-822. Chinese.

16. Bao Z, Chen D, Li B. Research on the therapeutic effect and adverse reactions of combination chemotherapy with NVB and TXT on nonsmall cell lung cancer. Chinese Journal of Clinical Pharmacology and Therapeutics. 2014;19:916-920. Chinese.

17. Jadad AR, Moore RA, Carroll D, et al. Assessing the quality of reports of randomized clinical trials: is blinding necessary? Control Clin Trials. 1996;17:1-12.

18. Moher D, Pham B, Jones A, et al. Does quality of reports of randomised trials affect estimates of intervention efficacy reported in meta-analyses? Lancet. 1998;352:609-613.

19. Higgins JP, Thompson SG, Deeks JJ, Altman DG. Measuring inconsistency in meta-analyses. BMJ. 2003;327:557-560.

20. Rodrigues-Pereira J, Kim JH, Magallanes M, et al. A randomized phase 3 trial comparing pemetrexed/carboplatin and docetaxel/carboplatin as first-line treatment for advanced, nonsquamous non-small cell lung cancer. J Thorac Oncol. 2011;6:1907-1914.

21. Vergnenegre A, Corre R, Berard H, et al; 0506 GFPC Team. Costeffectiveness of second-line chemotherapy for non-small cell lung cancer: an economic, randomized, prospective, multicenter phase III trial comparing docetaxel and pemetrexed: the GFPC 05-06 study. J Thorac Oncol. 2011;6:161-168.

22. Hanna N, Shepherd FA, Fossella FV, et al. Randomized phase III trial of pemetrexed versus docetaxel in patients with non-small-cell lung cancer previously treated with chemotherapy. J Clin Oncol. 2004;22: 1589-1597.

23. Karampeazis A, Vamvakas L, Agelidou A, et al. Docetaxel vs. vinorelbine in elderly patients with advanced non - small-cell lung cancer: a hellenic oncology research group randomized phase III study. Clin Lung Cancer. 2011;12:155-160.

24. Kudoh S, Takeda K, Nakagawa K, et al. Phase III study of docetaxel compared with vinorelbine in elderly patients with advanced non-smallcell lung cancer: results of the West Japan Thoracic Oncology Group Trial (WJTOG 9904). J Clin Oncol. 2006;24:3657-3663.

25. Krzakowski M, Ramlau R, Jassem J, et al. Phase III trial comparing vinflunine with docetaxel in second-line advanced non-small-cell lung cancer previously treated with platinum-containing chemotherapy. J Clin Oncol. 2010;28:2167-2173. 
26. Kubota K, Watanabe K, Kunitoh H, et al; Japanese Taxotere Lung Cancer Study Group. Phase III randomized trial of docetaxel plus cisplatin versus vindesine plus cisplatin in patients with stage IV non-small-cell lung cancer: the Japanese Taxotere Lung Cancer Study Group. J Clin Oncol. 2004;22:254-261.

27. Hong WK. The current status of docetaxel in solid tumors. An M. D. Anderson Cancer Center Review. Oncology (Williston Park). 2002;16: 9-15.

28. Crown J, O’Leary M. The taxanes: an update. Lancet. 2000;355: 1176-1178.

29. Fulton B, Spencer CM. Docetaxel. A review of its pharmacodynamic and pharmacokinetic properties and therapeutic efficacy in the management of metastatic breast cancer. Drugs. 1996;51:1075-1092.

30. Jin Y, Sun Y, Shi X, et al. Meta-analysis to assess the efficacy and toxicity of docetaxel-based doublet compared with docetaxel alone for patients with advanced NSCLC who failed first-line treatment. Clin Ther. 2014;36:1980-1990.

31. Moudi M, Go R, Yien CY, Nazre M. Vinca alkaloids. Int J Prev Med. 2013;4:1231-1235.

32. Bennouna J, Breton JL, Tourani JM, et al. Vinflunine - an active chemotherapy for treatment of advanced non-small-cell lung cancer previously treated with a platinum-based regimen: results of a phase II study. Br J Cancer. 2006;94:1383-1388.

33. Al-Saleh K, Quinton C, Ellis PM. Role of pemetrexed in advanced nonsmall-cell lung cancer: meta-analysis of randomized controlled trials, with histology subgroup analysis. Curr Oncol. 2012;19:e9-e15.
34. Smit EF, Mattson K, von Pawel J, Manegold C, Clarke S, Postmus PE. ALIMTA (pemetrexed disodium) as second-line treatment of non-smallcell lung cancer: a phase II study. Ann Oncol. 2003;14:455-460.

35. Li X, Wang H, Lin W, Xu Q. Efficacy of combining targeted therapy with pemetrexed or docetaxel as second-line treatment in patients with advanced non-small-cell lung cancer: a meta-analysis of 14 randomized controlled trials. Curr Med Res Opin. 2014;30:2295-2304.

36. Li R, Sun L, Wang J, Qian J, Wang Z, Jiao X. Pemetrexed versus docetaxel in second line non-small-cell lung cancer: results and subsets analyses of a multi-center, randomized, exploratory trial in Chinese patients. Pulm Pharmacol Ther. 2012;25:364-370.

37. Douillard JY, Laporte S, Fossella F, et al. Comparison of docetaxeland vinca alkaloid-based chemotherapy in the first-line treatment of advanced non-small cell lung cancer: a meta-analysis of seven randomized clinical trials. J Thorac Oncol. 2007;2:939-946.

38. Klionsky DJ, Abdalla FC, Abeliovich H, et al. Guidelines for the use and interpretation of assays for monitoring autophagy. Autophagy. 2012;8:445-544.

39. Sun CT, Xu X, Sheng W, Wang XW, Wen SL, Han JQ. A meta-analysis of pemetrexed-based doublet compared with pemetrexed alone for the second-line treatment of advanced non-small-cell lung cancer. Bratisl Lek Listy. 2014;115:233-237.
OncoTargets and Therapy

\section{Publish your work in this journal}

OncoTargets and Therapy is an international, peer-reviewed, open access journal focusing on the pathological basis of all cancers, potential targets for therapy and treatment protocols employed to improve the management of cancer patients. The journal also focuses on the impact of management programs and new therapeutic agents and protocols on

\section{Dovepress}

patient perspectives such as quality of life, adherence and satisfaction. The manuscript management system is completely online and includes a very quick and fair peer-review system, which is all easy to use. Visit http://www.dovepress.com/testimonials.php to read real quotes from published authors. 